\title{
MIDAS
}

Museus e estudos interdisciplinares

$8 \mid 2017$

Dossier temático "Objetos e museus: biografias, narrativas e vínculos identitários"

\section{Adelaide Duarte - Da Coleção ao Museu. O Colecionismo Privado de Arte Moderna e Contemporânea em Portugal}

\section{Luís Urbano Afonso}

\section{OpenEdition}

\section{Journals}

Edição electrónica

URL: http://journals.openedition.org/midas/1160

DOI: $10.4000 /$ midas. 1160

ISSN: 2182-9543

\section{Editora:}

Alice Semedo, Paulo Simões Rodrigues, Pedro Casaleiro, Raquel Henriques da Silva, Ana Carvalho

\section{Refêrencia eletrónica}

Luís Urbano Afonso, «Adelaide Duarte - Da Coleção ao Museu. O Colecionismo Privado de Arte Moderna e Contemporânea em Portugal », MIDAS [Online], 8 | 2017, posto online no dia 31 julho 2017, consultado no dia 25 setembro 2020. URL : http://journals.openedition.org/midas/1160 ; DOI : https://doi.org/ $10.4000 /$ midas. 1160

Este documento foi criado de forma automática no dia 25 setembro 2020.

\section{(1) 80

Midas is licensed under a Creative Commons Attribution-NonCommercial-ShareAlike 3.0 International License 


\title{
Adelaide Duarte - Da Coleção ao Museu. o Colecionismo Privado de Arte Moderna e Contemporânea em Portugal
}

\author{
Luís Urbano Afonso
}

\section{REFERÊNCIA}

Duarte, Adelaide. 2017. Da Coleção ao Museu. O Colecionismo Privado de Arte Moderna e Contemporânea em Portugal. Vol. 6. Coleção Estudos de Museu. Casal de Cambra: Caleidoscópio e Direção-Geral do Património Cultural. 427 páginas, ISBN:

978-989-658-431-3

1 O livro em apreço corresponde à dissertação que a autora apresentou à Universidade de Coimbra em 2012 para obtenção do grau de doutoramento em História, na especialização de Museologia e Património Cultural, sob orientação das Professoras Irene Vaquinhas (Universidade de Coimbra) e Lúcia Almeida Matos (Universidade do Porto). Além dos óbvios ajustamentos implicados na passagem de uma dissertação académica a um texto impresso, o conteúdo da obra não sofreu transformações significativas, mantendo-se fiel a uma expressão escrita e a uma argumentação que eram, desde a origem, de grande rigor e fundamentação. Porém, sendo o colecionismo privado de arte moderna e contemporânea um tópico muito dinâmico e volúvel, a autora atualizou o estudo introduzindo emendas e novas informações, através de notas de rodapé, que não interferem com o arranjo do texto original e com as conclusões alcançadas na altura. Estas pequenas adaptações somam-se à supressão de diversos excertos acessórios, sobretudo de natureza histórica, bem como à eliminação de vários gráficos patentes no trabalho original. Foram também excluídos, infelizmente, vários documentos relevantes que constavam dos anexos da dissertação, sobretudo as cópias dos acordos firmados entre os representantes das quatro coleções privadas estudadas pela autora e as quatro entidades públicas que as receberam. Estas supressões são contrabalançadas pelas atualizações já referidas, pelo acréscimo de novos títulos à lista 
bibliográfica final e pela construção de um exaustivo índice remissivo. É com estas mudanças, e com uma série de melhoramentos estilísticos, que o texto original é dado aos prelos na nova coleção "Estudos de Museus" da editora Caleidoscópio, apoiada pela Direção-Geral do Património Cultural.

2 A obra em análise organiza-se em duas partes. A primeira, mais breve (pp. 17-115), é de natureza contextual e teórica, abarcando um conjunto diversificado de temáticas, sendo alicerçada, sobretudo, em literatura secundária. Nesta parte do livro são definidos e estudados os conceitos de coleção, colecionador e colecionismo, apresentase uma história sumária do colecionismo de arte moderna e contemporânea na Europa e nos Estados Unidos, e é feita a revisão da literatura mais relevante dedicada a estes temas, abrangendo autores como Jean Baudrillard, John Elsner, Susan Pearce, Krzysztof Pomian e James Stourton. A autora carateriza de forma sintética o sistema da arte contemporânea, baseando-se em autores como Alexandre Melo, Raymonde Moulin e Francesco Poli, salientando o papel desempenhado pelas instituições museológicas nesse sistema. É apresentada ainda uma breve história dos mercados da arte entre os finais do século XIX e a atualidade, centrada na realidade francesa e norte-americana, destacando três colecionadores de referência que disponibilizaram as respetivas coleções ao público, nomeadamente Peggy Guggenheim, Giuseppe Panza e Charles Saatchi. A autora descreve também o lento e tortuoso processo de formação dos mercados de arte moderna e contemporânea em Portugal, a partir dos meados do século XX, destacando o papel pioneiro, e singular, da Galeria de Março (1952-1954). Na última secção desta primeira parte, a autora traça uma história abreviada de múltiplos museus e/ou coleções portuguesas de arte moderna e contemporânea, como o antigo Centro de Arte Moderna da Fundação Calouste Gulbenkian, a coleção da Caixa Geral de Depósitos, o Museu do Chiado, o Museu de Serralves, a coleção da sociedade de advogados PLMJ, a antiga coleção Ellipse do ex-banqueiro João Rendeiro, a coleção da Fundação Luso-Americana para o Desenvolvimento e ainda outras coleções privadas menos conhecidas.

3 A segunda parte do livro, bastante mais longa (pp. 117-304), assenta em trabalho de investigação inédito desenvolvido pela autora através do estudo de fontes primárias, consultadas em diversos arquivos especializados, públicos e privados. Estes dados são complementados com entrevistas e contactos estabelecidos com várias figuras fulcrais do mundo da arte moderna e contemporânea em Portugal, destacando-se Rui Mário Gonçalves e José-Augusto França, abrangendo experiências e testemunhos que recuam até aos meados do século XX. Esta segunda parte possui uma natureza bastante mais prática e informativa, sendo constituída por quatro estudos de caso. No essencial, a autora analisa os processos de formação, desenvolvimento e passagem para a esfera pública de quatro coleções portuguesas privadas de arte moderna e contemporânea, a saber: a) a coleção do crítico e historiador da arte José-Augusto França, constituída por 186 obras, doada à Câmara Municipal de Tomar e ao Museu do Chiado (pp. 120-165); b) uma seleção de 287 obras da coleção do galerista Manuel de Brito, cedida em regime de comodato à Câmara Municipal de Oeiras (pp. 166-209); c) a coleção de arte moderna e contemporânea do empresário José Berardo, exposta no Museu Coleção Berardo, sito no Centro Cultural de Belém, através do regime de comodato e constituída por 862 obras (pp. 210-254); d) a coleção de arte contemporânea do empresário António Cachola, cedida à Câmara Municipal de Elvas em regime de depósito de longa duração, sendo 
analisada através do acervo existente em 2011, ou seja, um total de 407 obras (pp. 255-296).

4 Uma das maiores riquezas deste estudo diz respeito, precisamente, à caraterização de cada uma das quatro coleções escolhidas, abrangendo quer a análise histórica e artística das obras que as compõem, especialmente no caso das coleções de arte portuguesa com maior lastro histórico, quer a interação que estabeleceram com os desenvolvimentos da história da arte em Portugal, sobretudo ao nível da pintura, desde os meados do século XX aos inícios do século XXI. Nesta perspetiva é particularmente importante o estudo que a autora apresenta das coleções de José-Augusto França e de Manuel de Brito, onde essa interação foi extremamente forte. De igual modo, a autora traça o perfil biográfico de cada colecionador, procurando sempre compreender como esse perfil se cruza com a formação e crescimento da respetiva coleção e, naturalmente, com as caraterísticas de cada uma. Nesse sentido a autora procura perceber quais as obras ou correntes artísticas presentes na coleção que possuem maior significado estético e emocional para cada colecionador.

5 A diversidade de realidades encontradas pela autora é particularmente evidente quando se compara o processo de formação das quatro coleções e os núcleos que as compõem. Por exemplo, a "não-coleção" ou "coleção involuntária" de José-Augusto França foi criada ao longo de meio século com obras de pequenas dimensões oferecidas pelos artistas com quem conviveu, sendo considerada pelo próprio como um "instrumento de trabalho". Sendo constituída por obras presenteadas, é uma coleção onde o colecionador quase nunca pôde escolher as obras que a incorporam, tratando-se de uma situação peculiar, mas com paralelo noutras coleções de críticos de arte e de alguns artistas. Situação distinta diz respeito à coleção criada ao longo de quatro décadas pelo mais importante galerista de arte contemporânea portuguesa do século XX, Manuel de Brito, fundador da Galeria 111. Esta coleção foi realizada de forma paralela à sua atividade como galerista, selecionando, essencialmente, obras dos artistas que representava e com os quais convivia, às quais somou diversas obras que intermediava no mercado secundário. $O$ contraste ainda é maior entre estes dois tipos de coleção e as coleções dos empresários José Berardo e António Cachola, iniciadas sob aconselhamento de terceiros, respetivamente Francisco Capelo e João Pinharanda. São duas coleções criadas de forma bastante acelerada e destinadas, desde a sua origem, a uma apresentação pública, razão pela qual devem ser classificadas como coleções com uma vocação institucional. Uma é constituída por arte moderna e contemporânea internacional (Coleção Berardo), representativa dos principais artistas e movimentos do século XX, outra é uma coleção aberta, em expansão, formada por arte contemporânea portuguesa (Coleção Cachola), sobretudo produzida entre 1990 e a atualidade. Nesse sentido, a escolha de três tipologias diferentes de coleções e colecionadores - um crítico/historiador da arte, um galerista e dois empresários enriquece significativamente o trabalho da autora, permitindo testemunhar as idiossincrasias de cada coleção.

6 Trata-se, pois, de um livro de grande qualidade, bem estruturado e apoiado numa exaustiva investigação original. Em todo o caso, existem alguns pontos que carecem de melhor esclarecimento e de maior problematização crítica. Em termos de clarificação, por exemplo, não é estabelecida uma diferença entre o tipo de gestão, os critérios de aquisição e as políticas expositivas de instituições museológicas públicas (ex. Centro Pompidou, Museu do Chiado) face a instituições museológicas fundacionais de base 
privada (ex. Solomon Guggenheim Museum, Whitney Museum, La Maison Rouge) ou dedicadas a uma só coleção privada (ex. Museu Coleção Berardo). De igual modo, não é estabelecida uma comparação entre o regime jurídico de constituição e manutenção de alguns museus privados de arte contemporânea estrangeiros mencionados (ex. Museu Ludwig, The Menil Collection) e os estudos de caso analisados na segunda parte do livro, para os quais, em contrapartida, essa informação é muito abundante e exemplarmente analisada pela autora. Perceber-se o modo como são estabelecidas as parcerias entre o Estado e os colecionadores privados noutros países, nomeadamente na Europa continental, permitiria contextualizar e avaliar melhor as parcerias realizadas em Portugal.

7 Carece de melhor clarificação, igualmente, a diferença entre os vários regimes que regulamentam a passagem das obras de arte de uma coleção privada para uma coleção pública: aquisições, transferências, legados, doações, depósitos e comodato. Nestes dois últimos casos, aliás, a explicação é remetida para duas notas de rodapé autónomas (notas 330 e 812) e desfasadas da secção onde tais questões são tratadas pela primeira vez (p. 80). A respeito da caraterização da coleção Manuel de Brito (pp. 183-187), feita a partir das 287 obras que figuram no contrato de comodato firmado entre a autarquia oeirense e a família Brito, subsiste a dúvida se as conclusões da autora acerca do gosto do colecionador e da proveniência e aquisição das peças dessa amostra são extensivas às quase 2000 obras que contemplam a totalidade da coleção.

8 Em termos de problematização crítica, por sua vez, a primeira questão que importaria discutir prende-se com o grau de convergência/divergência das quatro coleções analisadas face ao padrão do colecionismo privado de arte moderna e contemporânea em Portugal. 0 tratamento museológico destas quatro coleções é representativo de uma nova tendência no colecionismo português ou é algo que resulta do caráter excecional dessas coleções, nomeadamente no caso das coleções Berardo e Cachola?

9 A segunda questão respeita ao "mantra" da inexistência de uma tradição colecionista em Portugal, repetido com amargura pela maior parte dos críticos e historiadores da arte. Este livro, de facto, demonstra as enormes dificuldades que coartaram a criação e desenvolvimento do colecionismo de arte moderna e contemporânea em Portugal até há 50 anos. Porém, estas dificuldades e atrasos não devem ser confundidos com a inexistência de uma tradição colecionista em geral. Aliás, a autora também tem o mérito de documentar a existência, e a qualidade, do colecionismo de arte moderna e contemporânea em Portugal desde a década de 1960, como o testemunham as importantes coleções de Augusto Abreu e de Jorge de Brito. Esta tradição colecionista está condicionada, naturalmente, pela escala limitada da economia portuguesa, pela idiossincrasia das suas elites económico-financeiras e pela posição cultural periférica do país dentro da Europa. Mas os equívocos continuarão a perpetuar-se se persistirmos em confundir a escassa representatividade do colecionismo de obras dos grandes mestres do passado (ex. Ticiano, Rubens, Velázquez, Rembrandt, Goya, Manet, Picasso, etc.), ditada por razões económicas, com a inexistência de uma tradição de colecionismo de arte em Portugal.

Uma última questão, bastante mais relevante, incide sobre as consequências do processo que dá tema ao livro: quais as implicações políticas, culturais, éticas e financeiras decorrentes da passagem de coleções privadas para o usufruto público, sem que ocorra uma transferência da propriedade das mesmas? Estão nestas circunstâncias as coleções de Manuel de Brito, de José Berardo e de António Cachola, já que a coleção 
de José-Augusto França foi doada pelo próprio ao Estado português. Este tipo de parcerias corresponde efetivamente a ações mecenáticas de partilha cultural ou tem outras finalidades? Quais os benefícios obtidos pelas coleções e pelos colecionadores envolvidos nestas parcerias em termos fiscais? Até que ponto as escolhas privadas devem ser adotadas e validadas por instituições museológicas públicas ou financiadas com dinheiros públicos? Este tipo de parcerias sinaliza a crise dos estados democráticos europeus e a fragilidade das suas políticas públicas no domínio da cultura e da arte contemporânea? Porque razão é que a partilha de uma coleção privada tem de implicar a criação de uma nova instituição museológica, designada com o nome do colecionador, em vez de contribuir para enriquecer e complementar o acervo de um museu público já existente? Este tipo de perguntas demonstra quão necessário é discutir criticamente os benefícios e os inconvenientes destas autênticas parcerias público-privadas no âmbito da exposição da arte moderna e contemporânea em Portugal.

Em suma, o livro em apreço é um trabalho de elevado valor, construído através de uma metodologia clara e baseado numa exaustiva investigação original. É um livro que constitui uma referência no estudo da história das coleções de arte moderna e contemporânea em Portugal, contribuindo também para divulgar a história dos mercados da arte nos últimos 50 anos no nosso país. Porém, atendendo a estas qualidades, lamenta-se uma certa inibição na análise das vantagens e das desvantagens dos protocolos estabelecidos entre o estado e os representantes das quatro coleções privadas estudadas pela autora.

\section{AUTORES}

\section{LUÍS URBANO AFONSO}

ARTIS - Instituto de História da Arte da Faculdade de Letras da Universidade de Lisboa, Portugal, luis.afonso@letras.ulisboa.pt 